\section{What is already known on this topic}

Outcomes of screening mammography include benefits (reduced risk of death from breast cancer) and harms (physical and psychological adverse effects from screening and follow-up tests and detection of inconsequential disease)

Current information about screening mammography fails to meet women's needs for full and balanced information about these benefits and harms

\section{What this study adds}

This model of screening mammography presents quantitative information about the outcomes of screening in a form suitable to inform decisions about screening

It provides information about cumulative benefits and harms over the same time frame ( 10 years) for women aged $40,50,60$, and 70 years who are considering screening

is only a small chance of benefit but the stakes are high. Some women will be happy to choose the gamble even though they may experience anxiety, inconvenience, and physical adverse effects; other women will not. Clinicians may be able to use this information to support discussions with women about these possibilities and to support their patients in making a choice that is consistent with their own circumstances and values and preferences. As well as providing information for women aged 50-69 years, it may be useful for clinicians' discussions with patients in "out of target" age groups by making explicit the possible risks and benefits of a decision to be screened. We have incorporated these estimates into decision aids that are currently being tested in Australia. These methods can be applied to different populations and other screening contexts. The effect of such information on decision quality and screening participation is currently unknown but can be tested.

We thank Erin Mathieu for assistance with proofreading this paper.

Contributors: See bmj.com

Funding: This work was undertaken as part of the screening and test evaluation programme, funded by the National Health and Medical Research Council of Australia (grant No 211205).

Competing interests: None declared.

Ethical approval: Not required.

1 BreastScreen Australia and Australian Department of Health and Ageing. Who should have a mammogram? www.breastscreen.info.au/who/ index.htm (accessed 2 Feb 2005).

2 US Preventive Services Task Force. Screening for breast cancer. www.ahrq.gov/clinic/uspstf/uspsbrca.htm (accessed 2 Feb 2005).

3 General Medical Council. Seeking patients' consent: the ethical considerations November 1998. www.gmc-uk.org/global_sections/search frameset.htm November 1998. Www.

4 UK National Screening Committee. Second report of the UK national screening committee. www.nsc.nhs.uk/pdfs/secondreport.pdf (accessed 2 Feb 2005).

Thornton H, Edwards A, Baum M. Women need better information about routine mammography. BMJ 2003;327:101-3.

Barratt AL, Trevena L, Davey HM, McCaffery K. Use of decision aids to support informed choices about screening. BMJ 2004;329:507-10.

7 Drossaert CHC, Boer H, Seydel ER. Does mammographic screening and a negative result affect attitudes towards future breast screening? J Med Screen 2001:8:204-12.

8 Schwartz LM, Woloshin S, Fowler FJ, Welch HG. Enthusiasm for cancer screening in the United States. JAMA 2004;291:71-78.

9 Australian Institute of Health and Welfare. BreastScreen Australia monitoring reports 1998-99, 1999-2000 and 2000-2001. Cancer series numbers 25 and 26. Canberra: Australian Institute of Health and Welfare, 2003 (CAN 20 and CAN 21)

10 Australian Institute of Health and Welfare. BreastScreen Australia achievement report 1997-1998. Cancer series number 13. Canberra: Australian Institute of Health and Welfare, 2000 (CAN 8).

11 Queensland Health. BreastScreen Queensland annual statistical report for 1999. Brisbane: Queensland Health, 2001.

12 BreastScreen Victoria. BreastScreen Victoria 2000 and 2001 annual statistical reports. Melbourne: BreastScreen Victoria, 2002-3.

13 BreastScreen SA. BreastScreen SA statistical report 1999-2000. Adelaide: BreastScreen SA, 2003.

14 Van Zee KJ, Liberman L, Samli B, Tran KN, McCormick B, Petrek JA, et al. Long term follow-up of women with ductal carcinoma in situ treated with breast-conserving surgery: the effect of age. Cancer 1999;86:1757-67.

15 Kerlikowske K, Grady D, Rubin SH, Sandrock C, Ernster VL. Efficacy of screening mammography: a meta-analysis. JAMA 1995;273:149-54.

6 Glasziou P. Meta-analysis adjusting for compliance: the example of screening for breast cancer. J Clin Epidemiol 1992;45:1251-6.

17 Irwig L Glasziou P, Barratt A, Salkeld G. Review of the evidence about the value of mammographic screening in 40-49 year old women. Kings Cross, New value of mammographic screening in 40-49 year old women. Kings

(Accepted 9 February 2005)

doi 10.1136/bmj.38398.469479.8F
Directorate of

Obstetrics and Gynaecology, Luton and Dunstable Hospital NHS Trust, Luton LU4 0DZ

Peter C Reid consultant gynaecologist

Faizah Mukri senior house officer

Correspondence to: P C Reid

Peter.Reid@

ldh-tr.anglox.nhs.uk

BMJ 2005;330:938-9

\title{
Trends in number of hysterectomies performed in England for menorrhagia: examination of health episode statistics, 1989 to $2002-3$
}

\author{
Peter C Reid, Faizah Mukri
}

Twenty years ago $60 \%$ of patients with menorrhagia who were referred to a gynaecologist had a hysterectomy as treatment. ${ }^{1}$ Endometrial ablation was first described in the United Kingdom in 1989 and is a viable surgical alternative to hysterectomy. ${ }^{2}$ The levonorgestrel intrauterine system (Mirena, Schering Health) is highly effective in reducing menstrual bleeding and has been shown to reduce the numbers of patients proceeding to hysterectomy. ${ }^{3}$ It would be expected therefore that the numbers of hysterectomies would be falling. Nearly half of women referred to secondary care with menorrhagia, however, express a preference for hysterectomy, ${ }^{4}$ and it should be recognised that hysterectomy remains an excellent treatment for menstrual problems and brings high levels of patient satisfaction. We aimed to observe trends in the number of hysterectomies performed for menorrhagia in England.

This article was posted on bmj.com on 4 February 2005: http://bmj.com/ cgi/doi/10.1136/bmj.38376.505382.AE 


\section{Methods and results}

We examined NHS hospital episode statistics compiled from data submitted by over 300 NHS trusts in England for the years 1989-90 to 2002-3. The figures for 2001-2 and 2002-3 have not been adjusted to account for shortfalls in the number of records submitted.

No single international classification of diseases (ICD) code exists for menorrhagia, so data included several codes, from both the ninth and tenth revisions (ICD-9: 626.2, 626.8, and 627.0; and ICD-10: N92.0, N92.1, N92.4, N92.5, and N92.6). Operation codes for hysterectomy are Q07, Q08. We used the codes Q17 and Q16 combined with Y114 (microwave endometrial ablation) and Y118 (thermal balloon ablation) to determine the number of endometrial ablations. We analysed data for patients aged 20 to 60 years.

From 1989-90 to 1994-5 an average of 23056 hysterectomies a year were performed for menorrhagia in the NHS in England. Since 1995-6 there has been a sustained and substantial fall in this number (figure). In 2002-3, 8332 hysterectomies and 4921 endometrial ablations were performed, representing a reduction of $64 \%$ in the number of hysterectomies and a reduction of 43\% (13 $253 v 23284$ ) in the total number of operations for menorrhagia compared with 1989-90.

\section{Comment}

The number of hysterectomies for menorrhagia in England has fallen substantially to just over one third $(36 \%)$ of the number of a decade ago. The fall in hysterectomies is not due to endometrial ablation alone as nearly 10000 fewer operations are being performed a year.

Active education of good management of menorrhagia and promotion of effective medical management in primary care halves the number of referrals to secondary care but doubles the risk of surgery of those referred ${ }^{5}$ suggesting a neutral effect on hysterectomy. The fall cannot be attributed to more operations being performed in the private sector as hysterectomy numbers are falling similarly in that sector (David Horwell, personal communication).

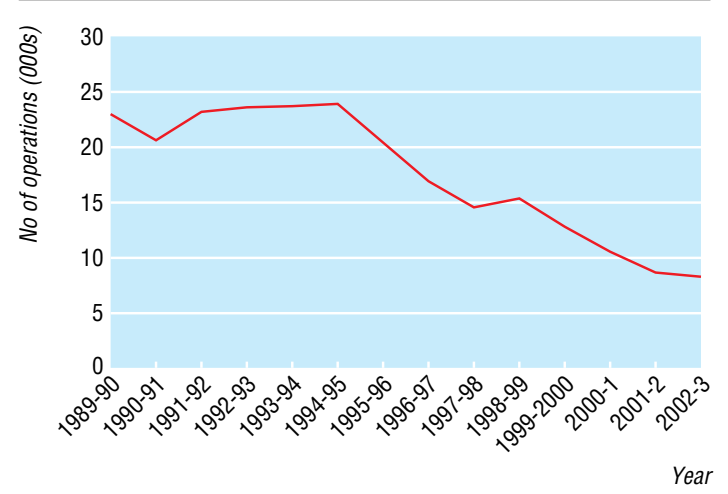

Number of hysterectomies for menorrhagia from 1989-90 to 2002-3 in NHS trusts in England

\section{What is already known on this topic}

Hysterectomy is a common and effective management for heavy periods

New technologies, including endometrial ablation and the levonorgestrel intrauterine system, have the potential to reduce the number of hysterectomies

\section{What this study adds}

The number of hysterectomies performed for heavy periods is only a third that of a decade ago

Although not licensed for treating menorrhagia until January 2001, Mirena has been used as a contraceptive method since May 1995, which coincides with the start of the fall in hysterectomies. The hypothesis is that Mirena is already in widespread use and having a considerable impact on the number of hysterectomies being performed. The epidemiology of Mirena for the management of menorrhagia in primary care remains to be elucidated and should be answered by the ECLIPSE study (International Standard Randomised Controlled Trial Number 86566246 (www.controlledtrials.com/isrctn)). Care should be taken with this interpretation as the use of Mirena for the management of menorrhagia is a relatively new development, and as over half of patients who have a Mirena inserted in randomised studies go on to have a hysterectomy ${ }^{4}$ we may yet see an increase in surgery over the next three or four years.

Being aware of this very substantial fall in hysterectomies is important and may be helpful in counselling patients before referral. The data also suggest that hysterectomy is no longer the usual management for menorrhagia in secondary care and have great implications for the future surgical training of gynaecologists.

Contributors: PCR had the original idea for the study, analysed the data, wrote the paper, and is the guarantor. FM helped with the design and data acquisition.

Funding: None.

Competing interests: PCR has been the recipient of grants from the NHS for research into endometrial ablation and Schering Finland for research into the levonorgestrel intrauterine system (Mirena).

Ethical approval: None required.

1 Coulter A, Bradlow J, Agass M, Martin-Bates C, Tulloch A. Outcomes of referrals to gynaecology outpatient clinics for menstrual problems: an audit of general practice. Br J Obstet Gynaecol 1991;98:789-96.

2 Aberdeen Endometrial Ablation Trials Group. A randomised trial of endometrial ablation versus hysterectomy for the treatment of dysfunctional uterine bleeding: outcome at four years. BrJ Obstet Gynaecol 1999;106:360-6

3 Hurskainen R, Teperi J, Rissanen P, Aalto A-M, Grenman S, Kivelä A, et al. Clinical outcomes and costs with the levonorgestrel-releasing al. Clinical outcomes and costs with the levonorgestrel-releasing
intrauterine system or hysterectomy for treatment of menorrhagia. Ran-

domised trial 5-year follow-up. JAMA 2004;291:1456-63.
Kennedy ADM, Sculpher MJ, Coulter A, Dwyer N, Rees M, Horsley S, et al. A multicentre randomised controlled trial assessing the costs and benefits of using structured information and analysis of women's preferences in the management of menorrhagia. Health Technology Assessment 2003; $7(8): 1-45$.

5 Fender GRK, Prentice A, Nixon RM, Gorst T, Duffy SW, Day NE, et al. Management of menorrhagia: an audit of practices in the Anglia menorrhagia education study. BMJ 2001;322:523-4.

(Accepted 11 January 2005)

doi 10.1136/bmj.38376.505382.AE 